\title{
MAPEAMENTO DE COBERTURA E DO USO DA TERRA: CRÍTICAS E AUTOCRÍTICAS A PARTIR DE UM ESTUDO DE CASO NA AMAZÔNIA BRASILEIRA
}

Alex Mota dos Santos ${ }^{1}$ Fabrizia Gioppo Nunes ${ }^{2}$

Resumo: Os mapeamentos de cobertura e do uso da terra são produtos cartográficos empregados em diversas pesquisas, pois servem de bases aos modelos hidrológicos, modelos de cenários futuros, de perdas de solos, dentre outros. Assim, tendo em vista a importância do mapeamento de cobertura da terra, o artigo tem como objetivo apresentar um estudo de caso para evidenciar críticas e autocríticas aos trabalhos realizados. A metodologia empregada foi a clássica, envolvendo o processamento digital de imagens em ambiente de sistema de informação geográfica. Os resultados revelaram que a presença das unidades de conservação federal e terras indígenas contribuíram para que 64,03\% da área mapeada esteja recoberta pela classe Vegetação Natural - Florestal. A classe de uso Área Antrópica, constituída pelas atividades consorciadas de agricultura e pastagem, mais recorrentes, ocupa 17,26\% do município de Porto Velho.

Palavras-chave: Sensoriamento remoto. Mapeamentos temáticos. Padrão de desmatamento.

\section{MAPPING COVERAGE AND LAND USE: CRITICISM AND SELF-CRITICISM BASED ON A CASE STUDY IN THE BRAZILIAN AMAZON}

Abstract: The mapping of coverage and land use are cartographic products used in several surveys, as they serve as bases for hydrological models, models of future scenarios, of soil losses, among others. Thus, in view of the importance of land cover mapping, the article aims to present a case study to highlight criticism and selfcriticism of the work carried out. The methodology used was the classic one, involving digital image processing in a geographic information system environment. The results revealed that the presence of federal conservation units and indigenous lands contributed to $64.03 \%$ of the mapped area being covered by the Natural Vegetation - Forestry class. The antrópica area use class, consisting of the most recurrent agricultural and grazing activities, occupies $17,26 \%$ of the municipality of Porto Velho.

Keywords: Remote sensing. Thematic mapping. Deforestation pattern.

\section{MAPEAMENTO DE COBERTURA Y HACER USO DE LA TERRA: CRÍTICAS Y AUTOCRÍTICAS A PARTIR DE NUESTRO ESTUDIO DE CASO EN LA AMAZONIA BRASILEIRA}

Resumen: Los mapeamentos de cobertura y el uso de la tierra son productos cartográficos empregados en diversas pesquisas, servicios de bases de los modelos hidrológicos, modelos de cenos futuros, de perdas de solos, dentre outros. Assim, tendo em vista a importância do mapeamento de cobertura da terra, o artigo tem

\footnotetext{
${ }^{1}$ Universidade Federal de Goiás, Departamento de Engenharia de Transportes, Aparecida de Goiânia, Brasil, alexmota@ufg.br, https://orcid.org/0000-0002-5156-3968

2 Universidade Federal de Goiás, Instituto de Estudos Socioambientais, Goiânia, Brasil, fabrizia@ufg.br, https://orcid.org/0000-0001-6159-4701
} 
como objetivo apresentar um estudo de caso para evidenciar críticas e autocríticas aos trabalhos realiza una metodología empregada para una práctica clásica, envolviendo o procesando digitalmente imágenes en el ambiente de un sistema de información geográfica. Los resultados revelados en la presentación de las unidades de conservación federal y las tierras indígenas contribuyen al 64,03\% del área mapeada esteja recoberta pela classe Vegetação Natural - Florestal. Una clase de uso Área Antrópica, constituida por las actividades consorciadas de agricultura y pasta, más registradores, ocupación $17,26 \%$ del municipio de Porto Velho.

Palabras clave: Teledetección. Mapeo temático. Patrón de deforestación.

\section{Introdução}

Os mapeamentos de coberta e do uso da terra são produtos cartográficos empregados em diversas pesquisas, pois as informações neles disponibilizadas servem de base aos modelos clássicos de estimativas de perdas de solo (WISCHMEIER e SMITH, 1978), ao estudo da ecologia de paisagem (CASIMIRO, 2000), dos modelos hidrológicos (SANTOS et al., 2010), mapeamento de pressões antrópicas (SANTOS e GOMIDE, 2015), estimação e cartografia das mudanças dos padrões de reflectâncias de alvos terrestres (MELO e SOUZA, 2016), mapeamento das territorialidades e seus conflitos (SANTOS e MENDONÇA, 2016), análise dos riscos geoambientais e suas relações com o ordenamento territorial (MELO, 2016), modelos de cenários futuros (OLIVEIRA et al., 2018), dentre outros. No que se refere ao uso da terra e as mudanças de cobertura, Kaul e Sopan (2012), afirmam que esses estudos se tornaram componentes centrais nas estratégias atuais para gerenciar os recursos naturais e monitorar as alterações ambientais.

Para o Instituto Brasileiro de Geografia e Estatística - IBGE (2013) os mapeamentos de cobertura e uso da terra ganham destaque em função da necessidade de garantir a sustentabilidade sócioecológica diante das questões ambientais, sociais e econômicas a eles relacionadas e trazidas à tona nos debates sobre o desenvolvimento sustentável. Além disso, para Araújo Filho et al. (2007, p. 171), esse tipo de mapeamento é "essencial para fornecer subsídios aos programas de monitoramento ambiental, preservação da biodiversidade, zoneamento ambiental e socioeconômico e ocupação racional do espaço físico".

Portanto, mapear a cobertura e o uso da terra é um processo importante, necessário e contínuo, pois as superfícies terrestres são constantemente territorializadas, desterritorizadas e reterritorializadas, pelas forças do capital hegemônico, forças locais e, em menor escala, pelas comunidades tradicionais. Isso ocorre, pois segundo Melo e Souza (2016, p. 171), há "uma constante necessidade e demanda de novas áreas para expansão das poligonais urbanas e agrárias". 
Assim, muitos dos mapeamentos dessas áreas são realizados por pesquisas isoladas (BUTT et al., 2015; ALMEIDA et al., 2016; HASSAN et al., 2016), mas também pelos governos federativos, a exemplo do mapeamento realizado pelos países da comunidade europeia que deu origem ao inventário de classificação padronizada do CORINE Land Cover - CLC (FERANEC et al., 2016). Esse inventário de mapeamento da cobertura do solo foi iniciado em 1985. As atualizações foram produzidas em 2000, 2006, 2012 e 2018. Consiste em um inventário de cobertura do solo em 44 classes.

No Brasil, o pioneirismo é do Instituto Nacional de Pesquisas Espaciais (INPE), que vem produzindo dados em extensão espacial do desmatamento na Amazônia desde 1988, por meio do Programa de Monitoramento do Desmatamento no Brasil - Amazônia Legal (PRODES). A partir do ano de 2010 foi lançado o TerraClass, que é um complemento para o PRODES, adicionando informações sobre conversão de uso da terra, distribuição espacial do uso e cobertura do solo e estatísticas regionais nas áreas desmatadas até 2008 (ALMEIDA et al., 2016). Além do INPE, o IBGE apresentou o mapeamento do uso do solo do Brasil na escala 1/1.000.000, cuja produção não é regular, sendo a última atualização datada no ano de 2014.

Nesse sentido, dada a importância desses produtos, Soares (2020) realizou uma análise comparativa de mapeamentos de uso e cobertura do solo, entre as metodologias do TerraClass Cerrado 2013 e Corine Land Cover (CLC), para um município da região Centro-Oeste brasileira. Segundo o autor "O TerraClass Cerrado possui uma capacidade de mapeamento de dez classes de uso e cobertura do solo, onde se agregam classes: natural, agropecuária, pastagens, urbanas, água e mineração, numa escala de 1:250.000", sendo assim, mais compatível as características fisiográficas das paisagens brasileiras que o modelo CLC (SOARES, 2020, p. 5).

Entretanto, não podemos esquecer da contribuição do Manual Técnico de Uso da Terra, produzido pela equipe técnica do IBGE. Em sua terceira edição, este documento traz uma concepção aprimorada do Sistema de Classificação de Uso da Terra com a adoção de princípios básicos, nomenclaturas e ênfase à procedimentos metodológicos automatizados (IBGE, 2013). Esse manual é voltado a apoiar os interessados em mapear as explorações dos recursos terrestres e tem servido de base metodológica a diversos trabalhos, de refinamento da escala espacial, em âmbito nacional. 
Tendo em vista a importância do mapeamento de cobertura e uso da terra, este artigo tem como objetivo apresentar um estudo de caso, para evidenciar críticas e autocríticas aos trabalhos realizados. Serve de guia prático a partir da recomendação de pesquisas clássicas realizadas na Amazônia Legal. Além disso, diferente de outros estudos esse artigo apresenta orientações práticas para que os interessados no assunto possam aprofundar suas análises. Essas orientações serão apresentadas a partir do Projeto de Extensão Geotecnologias na Rede, elaborado por professores e estudantes de diversos cursos da Universidade Federal de Goiás UFG.

\section{Materiais e Métodos}

A metodologia de mapeamento das coberturas e dos usos da terra na Amazônia, já é consolidada nas literaturas clássicas e é realizada por meio de métodos indiretos, especialmente a partir do processamento digital de imagens em Sistemas de Informação Geográfica (SIGs). Nesse sentido, as possibilidades são inúmeras, pois a oferta de imagens gratuitas, especialmente aquelas de média e alta resolução espacial ${ }^{3}$ é grande. Contudo, é preciso reconhecer as limitações, pois os territórios políticos administrativos na Amazônia são 'enormes', se comparados com outros, territórios do país. Na Amazônia, o domínio dos municípios, das terras indígenas e das unidades de conservação recobrem áreas mais extensas do que as de outros estados. Desse modo, o recorte territorial selecionado foi o município, no caso, o município de Porto Velho (Figura 1).

\footnotetext{
${ }^{3}$ Não há consenso, mas adotou-se a classificação de resolução altíssima (centimétrica, exemplo 50 $\mathrm{cm}, 1$ metro, QuickBird), alta (métrica, exemplo LANDSAT, CBERS, 20/30 metros), moderada (alguns sensores do MOLDIS, 250 metros). Ferreira et al. (2007) classifica as imagens CBERS como de média resolução espacial.
} 
Figura 1 - Localização do Município de Porto Velho.

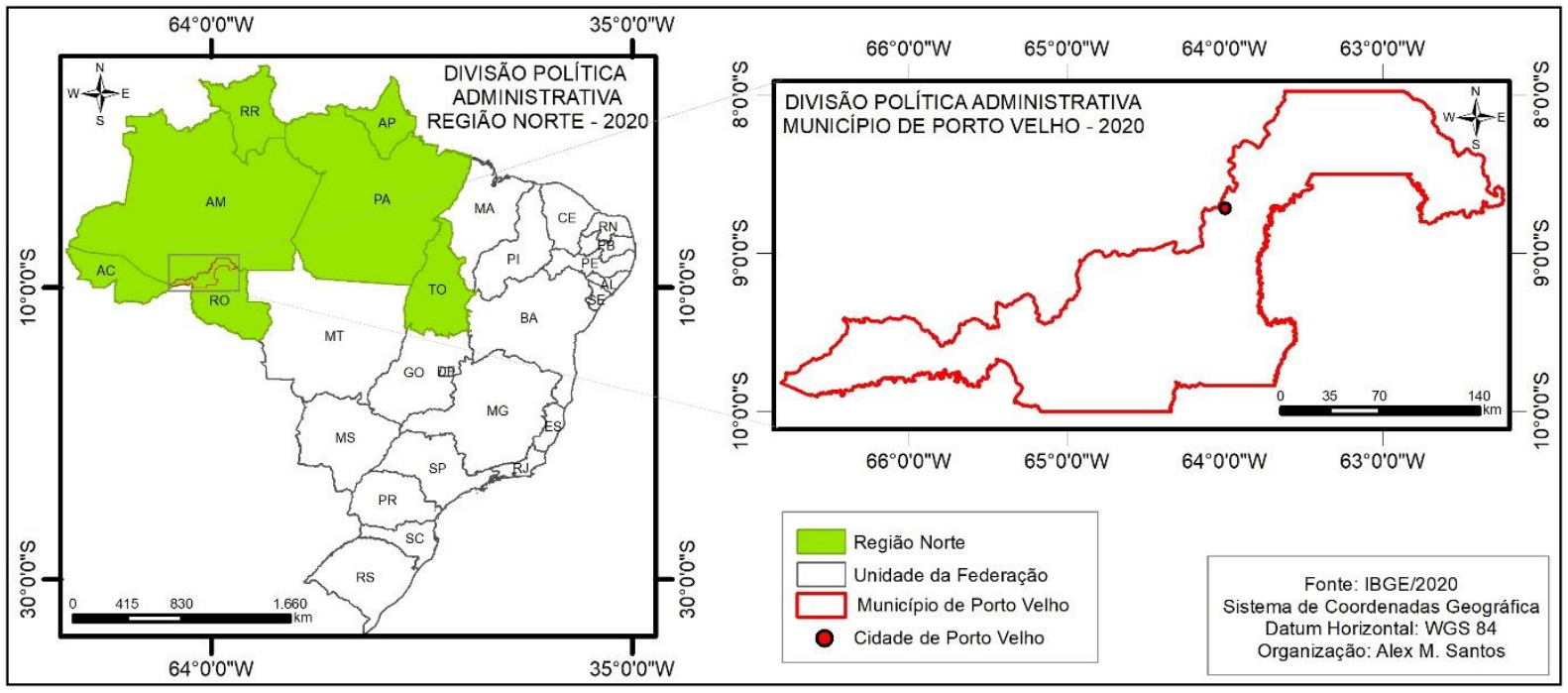

Fonte: elaborado pelos autores com dados do IBGE.

O município de Porto Velho possuí área de 34.090,954km². No interior de sua delimitação é possível identificar uma grande cidade, a capital, inúmeros e pequenos povoados e áreas especiais como: terras indígenas e unidades de conservação. Além disso, segundo o Monitoramento do Desmatamento da Floresta Amazônica Brasileira por Satélite, Porto Velho é o segundo município do norte brasileiro, com maior área desmatada, até o ano de $2018\left(10.199,6 \mathrm{~km}^{2}\right)$, o que justifica a sua seleção ${ }^{4}$. Outras características do município de Porto Velho revelam que o mesmo possui a maior população residente do estado de Rondônia. Nesse sentido, segundo o último censo de 2010 a população era de 428.527 habitantes, entretanto as estativas mais recentes revelam que a população é de 529.544 habitantes.

$\mathrm{Na}$ perspectiva da escolha de imagens mais adequadas às escalas amazônicas, parece razoável, reconhecer que imagens de sensores de resolução alta, a exemplo dos sensores: Regular Multispectral Camera (MUX), do China-Brazil Earth Resources Satellite (CBERS); Operational Terra Imager (OLI), do Land Remote Sensing Satellite (LANDSAT) e o sensor Short Wave Infrared (SWIR), do SENTINEL entre outros, são os mais adequados aos estudos à nível municipal. Invariavelmente, essas imagens possibilitam mapeamentos à escala de 1/50.000, podendo ser detalhada a partir do conhecimento de campo do pesquisador (BOGGIONE et al., 2009).

\footnotetext{
${ }^{4}$ Além disso, Porto Velho, é dentre "os grandes municípios desmatados", aquele que um dos pesquisadores, responsáveis por esse texto tem maior conhecimento de campo, devido as suas pesquisas com foco no desmatamento em áreas de terras indígenas no estado de Rondônia, dos últimos 8 anos.
} 
A partir da análise da área do município de Porto Velho, usado como estudo de caso ${ }^{5}$, observou-se que as imagens mais recentes (ano de 2019) são aquelas captadas pelos sensores dos satélites LANDSAT e CBERS. Assim, foram necessárias seis cenas do satélite LANDSAT, versão 8 , sensor OLI para recobrir toda área de estudo. Para o satélite CBERS, sensor MUX, seriam necessárias onze cenas, caso este fosse selecionado. Porém, o uso destas imagens implica em problemas técnicos relacionados a dinâmica da resolução temporal. Do LANDSAT, seis cenas revelam quatro órbitas que não são realizadas no mesmo dia. Essa dinâmica é agravada ainda mais, se os pesquisadores optassem pelo uso das imagens captadas pelo sensor MUX do CBERS, pois onze órbitas implicariam em mais dias de passagens, ou seja, na necessidade de se realizar o mapeamento do município com imagens de dias distintos.

Por outro lado, o sensor MUX do CBERS apresenta resolução radiométrica de 8 bits, valor que extrapola em muito o necessário para mapeamentos de cobertura e do uso da terra. O sensor OLI, do LANDSAT, apresenta 16 bits, o que torna o processamento moroso, exigindo esforço computacional maior. Apesar disso, e diante da possibilidade de computadores pessoais mais robustos, optou-se neste trabalho pelas imagens do sensor OLI, LANDSAT-8, conforme a figura 2 que representa o mosaico de aquisição das imagens.

Figura 2 - Mosaico das órbitas-pontos das imagens LANDSAT, sensor OLI utilizadas na pesquisa.

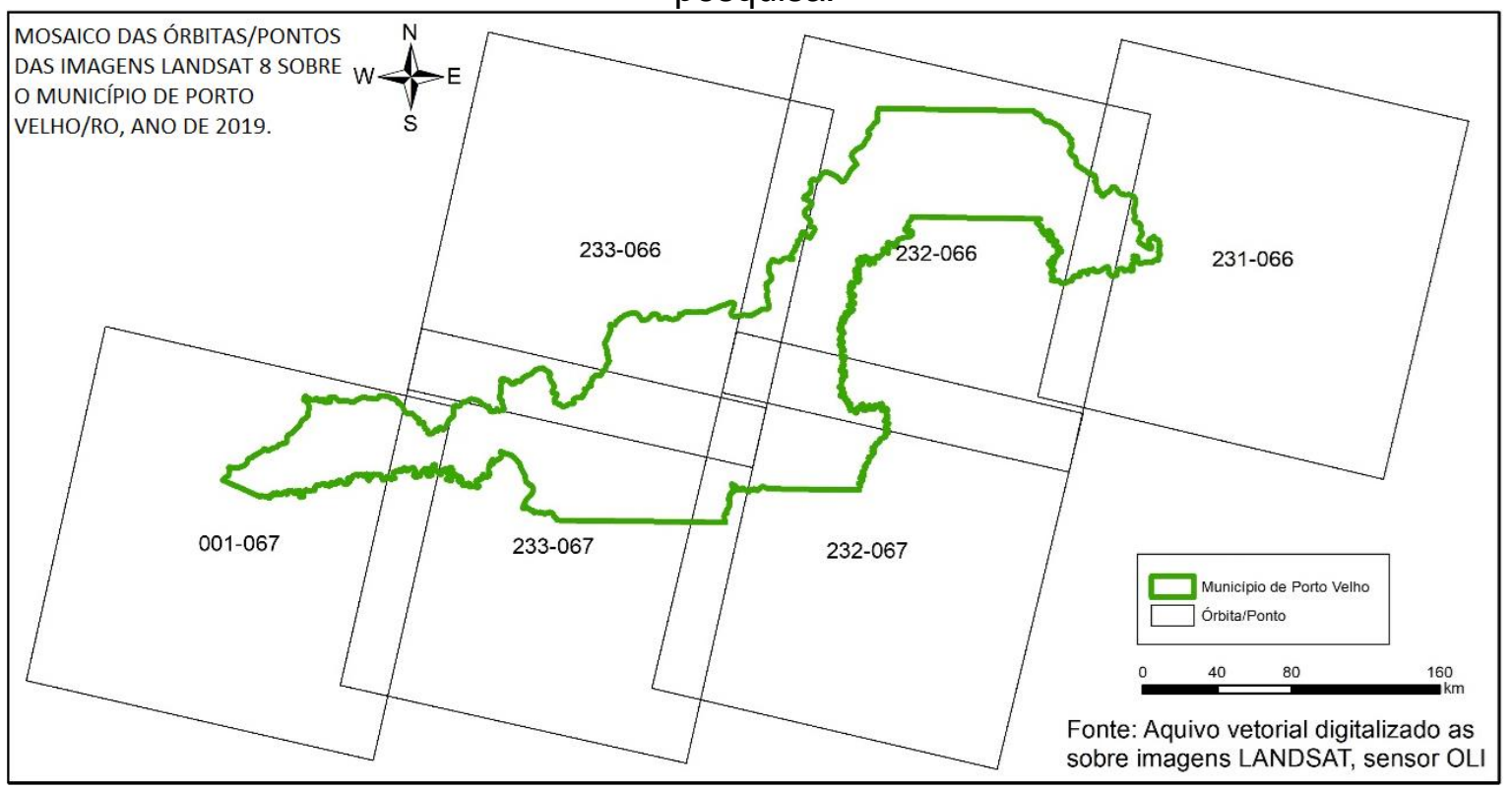

Fonte: elaborado pelos autores com dados digitalizados sobre as imagens LANDSAT, sensor OLI.

\footnotetext{
${ }^{5}$ Estuda situações reais que deram certo para se chegar a resultados de igual êxito, é um método científico comum e que apresenta vantagens.
} 
Após adquiridas as imagens e realizada a criação do Banco de Dados, com o recorte das imagens, para o polígono que envolve o município, elaborou-se a composição colorida RGB das bandas 4, 5 e 6 do sensor OLI. Segundo Santos (2014), estas bandas foram associadas a composição colorida, que fornece o sistema falsa cor, em que as cores dos alvos terrestres são representadas o mais próximo da visão do olho humano, por isso mais adequadas para análise em tela.

Assim, a partir da definição das imagens avançou-se para os procedimentos de tratamento digital de imagens descritos a seguir. A referida descrição apresenta dicas das etapas necessárias para a sua replicação. Serve como orientações básicas das teorias e práticas, capazes de dialogar com todas as etapas dos procedimentos de classificação digital de imagens, direcionadas a elaboração de mapas temáticos de cobertura e uso da terra.

\section{Processamento de imagens orbitais}

Amplamente explorado nas pesquisas cujo recorte espacial é a Amazônia, o processamento digital de imagens é um procedimento extremamente complexo. Apesar disso, muitos autores se apropriam de um SIG, realizam coletas de imagens, apresentam seus resultados, mas ignoram a indicação do classificador utilizado. Por exemplo, esses pesquisadores não revelam se o classificador é por região ou por pixel, nem as referências básicas utilizadas nas análises e/ou especificam a classificação e as regras de decisão operadas e sua validação, como descrito por Câmara et al. (1996).

Para que a técnica possa ser replicada é grave quando se ignora a performance do algoritmo de classificação utilizado, ou a análise de exatidão/acurácia. Em alguns casos, nem se quer apresentam parâmetros básicos que são exigidos em alguns classificadores por região, como a área de pixel e similaridade. Esses são parâmetros estatísticos essenciais, que permitem ao leitor, avaliar a 'qualidade' e os limites do trabalho como um todo, portanto não deveriam ser ignorados.

Assim, recomenda-se a leitura de Congalton (1991), que faz uma análise crítica dos critérios clássicos para avaliar e comparar a exatidão de mapeamentos de cobertura da terra. Bem como, do artigo de Ferreira et al. (2007) que apresentam um estudo de caso no município de Lavras-MG, para avaliar a exatidão da classificação de fragmentos de matas em imagem do satélite CBERS-CCD. 
Em domínio nacional, não podemos esquecer, que uma das ferramentas mais robustas, gratuitas e em língua portuguesa, para processamento digital de imagens é o Sistema para Processamento de Informações Georreferenciadas (SPRING), desenvolvido pelo INPE. Apesar de empiricamente serem observados diversos relatos na dificuldade de operação desse sistema, destaca-se o fato de que 0 mesmo exige, durante o processamento digital de imagens, que o operador tenha conhecimentos teóricos e técnicos integrados, para realizar qualquer função de analista em sensoriamento remoto.

Além disso, o mais importante no SPRING é a apresentação automática da estatística descritiva que permite a análise de confusão das amostras coletadas e a produção automática da matriz de erro do processo de classificação. Segundo Ferreira et al. (2007), os principais índices de acuracidade são: Erro de Omissão, Erro de Comissão, Acurácia Geral e Coeficiente Kappa. Todos esses métodos são descritos pelos referidos autores (FERREIRA et al., 2007). Ainda segundo Ferreira et al. (2007, p. 888), "através da estatística descritiva obtém-se o índice de Exatidão Global, em que se divide o total de pixels classificados corretamente (diagonal da matriz) pelo número total de pixels da matriz". Esse procedimento responde à pergunta: Qual o grau de concordância entre a imagem classificada e o terreno?

Em outros SIGs, caso do Qgis, a classificação e a análise da qualidade do procedimento são processos distintos. Acredita-se que por isso, os "analistas pouco treinados" ignoram essa fase. No caso do SPRING, este apresenta inconsistência quando o usuário aplica o método de classificação supervisionada a partir do classificador Bhattacharya, pois o resultado da análise revela que a Exatidão do produtor é igual a Exatidão do usuário, revelando sempre $100 \%$.

Contudo, a experiência tem revelado que a classificação pelo algoritmo Bhattacharya é a mais adequada para os mapeamentos na Amazônia, pois reduz a abstenção no processo de classificação. Quando ocorre abstenção, significa que o classificador supervisionado 'não tomou a decisão' de enquadrar uma amostra coletada, ou mais, em nenhuma das classes estabelecidas.

Assim, neste trabalho, optou-se pela aplicação do método supervisionado de classificação Bhattacharya, por região, que requer como uma de suas etapas a segmentação. Segundo Santos (2014, p. 31),

"Para a segmentação é necessário determinar um limiar de separabilidade denominada similaridade, que é um valor adimensional e está relacionado com as características da imagem, ou seja, um limiar adequado para uma determinada imagem pode se mostrar ineficaz para outra. Assim, o critério de similaridade baseia-se 
em um teste de hipótese estatístico que testa a média entre as regiões. A seguir, divide-se a imagem em um conjunto de subimagens e então se realiza a união entre elas, segundo um limiar de agregação definido.

A experiência tem revelado que o referido limiar depende da resolução radiométrica. Portanto, para imagens do sensor OLI da região Amazônica recomenda-se testes de hipótese do limiar que partirá do valor 500 . Nessa pesquisa, o teste revelou o limiar de similaridade 700 e a área de pixel de 30 (que é a medida do lado de um pixel). Para as imagens do CBERS e LANDSAT, versões $5 \mathrm{e}$ 7, em que a resolução radiométrica são 8 bits, o teste poderá partir dos valores 15 ou 20, ou seja, valores mais baixos. Definidos os parâmetros foi aplicado a segmentação no mosaico das imagens.

O SPRING, assim como outros SIGs, permite ainda a conversão dos dados raster em vetorial para a edição pós-classificação, elaboração dos mapas temáticos e análises quantitativas das classes de cobertura e uso da terra.

A partir das recomendações, críticas e autocríticas é apresentado na figura 3 o fluxograma com a síntese dos procedimentos necessários para o mapeamento da cobertura da terra, por intermédio da técnica de processamento digital de imagens de sensoriamento remoto, orbital e suborbital. As informações foram agrupadas em obrigatórias e optativas, conforme aplicadas nessa pesquisa. Nesse sentido, é importante referir que alguns procedimentos podem receber outras denominações, que depende do SIG utilizado.

Figura 3 - Síntese da metodologia aplicada. Os retângulos revelam atividades não obrigatórias, e os círculos são os procedimentos obrigatórios.

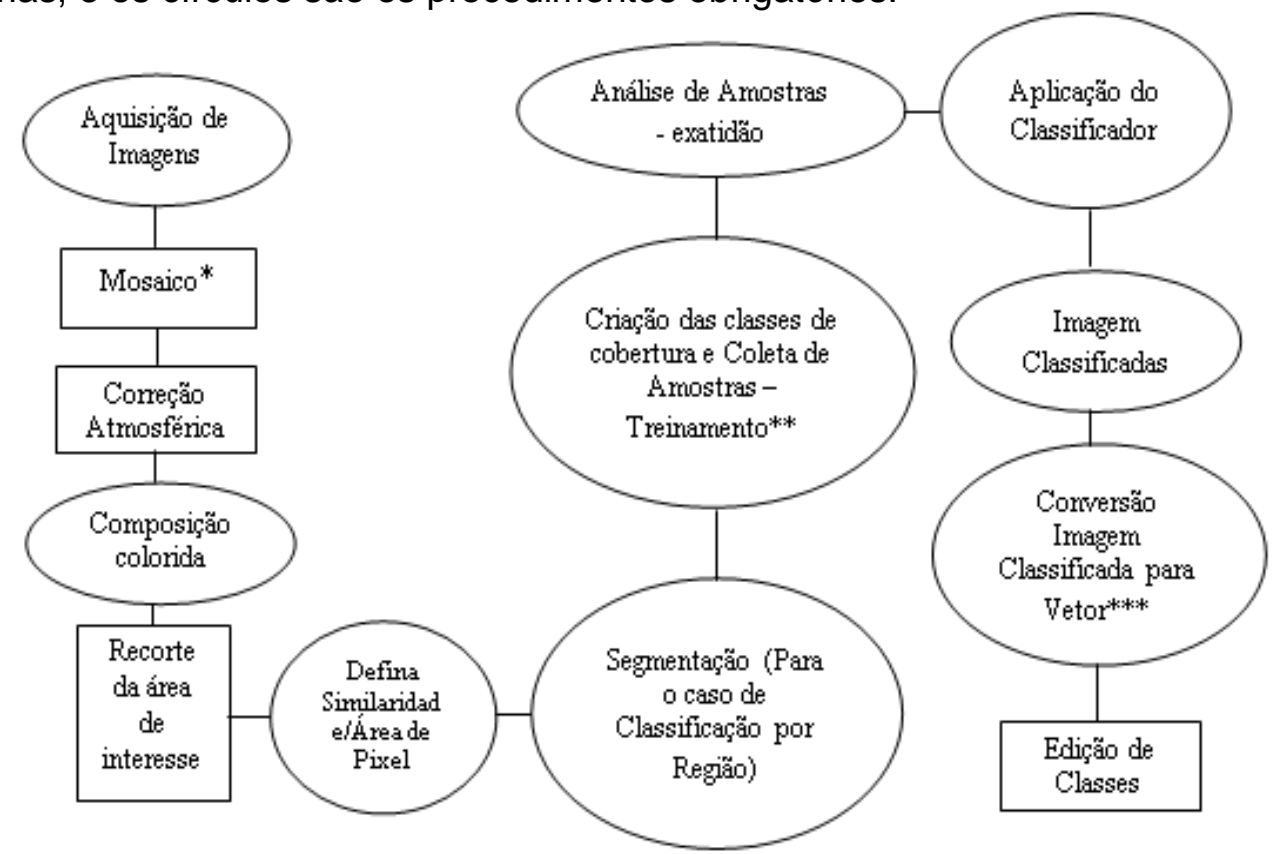

Fonte: elaborado pelos autores. 
A etapa de mosaico ${ }^{6}$ não foi descrita, pois é operação simples já que as imagens vêm georreferenciadas, sendo somente obrigatória para áreas extensas, logo após realizada a aquisição das mesmas. Nesse sentido, é importante referir que o Instituto Nacional de Pesquisas Espaciais (INPE), recomenda a correção geométrica, especialmente o registro de imagens, pois é reconhecido os erros sistemáticos das imagens de satélites. Segundo Bessa (2005, p. 22), esses erros "têm várias causas, dentre elas as distorções ocasionadas pelo movimento relativo entre a rotação da Terra e a translação do satélite, durante a aquisição da imagem".

Além disso, para classificadores supervisionados por pixel, a coleta de amostras (treinamento**) se dá diretamente na imagem e nos classificadores supervisionados por região, diretamente sobre os segmentos criados. Nessa etapa é desejável que o pesquisador conheça as chaves de classificação existentes. No Brasil, o documento oficial é de fácil acesso, e como já mencionado está disponível no Manual Técnico de Uso da Terra do IBGE (2013). Contudo, recentemente o pesquisador precisa conhecer a chave de classificação do TerraClass.

Assim, para a utilização do algoritmo Bhattacharya ${ }^{7}$ adotou a chave de classificação do IBGE (2013). De todas as classes catalogadas pelo instituto, foram mapeadas no município de Porto Velho: Áreas Antropizadas Agrícolas, Área de Vegetação Natural - Florestal, Área de Vegetação Natural - Florestal - Degradada, Corpo de Água Continental, Área de Mineração, Área Antrópica Agrícola Pastagem, Área de Vegetação Natural - Florestal - Campestres e Área Urbanizada. As classes Área Alagadiças, Banco de Areia, Fumaça, Queimadas e Sombra não são apresentadas pelo IBGE, entretanto, foram incorporadas nessa pesquisa, devido sua presença na área de estudo.

Como referido, o classificador Bhattacharya, apresentou limitações da análise da exatidão das amostras. Assim, aplicou-se a ferramenta Accuracy Assessment of Thematic Maps (AcATaMa) ${ }^{8}$ do software Qgis, como uma alternativa a resolução do problema e que também é um SIG livre e gratuito.

A última etapa, de conversão do arquivo matricial classificado para vetor $\left(^{* * *}\right)$ foi realizada concomitantemente com o processo de classificação, a exemplo de alguns SIGs, como o Qgis.

\footnotetext{
${ }^{6} \mathrm{O}$ mosaico permite que cenas espacialmente adjacentes sejam integradas à uma única cena, fato que favorece e simplifica o processamento (SANTOS, 2014).

7 Para guia do procedimento ver links https://www.youtube.com/watch?v=d66hjTCwUUc e https://www.youtube.com/watch?v=A4P6WyOEbel\&t=12s

8 Para guia do procedimento ver o link https://www.youtube.com/watch?v=P--Y3fXmnpQ\&t=152s
} 
A efeito de uma melhor performance da classificação é importante ressaltar, que os arquivos vetoriais elaborados através da conversão matriz - vetor podem ser editados, a partir de sua sobreposição as imagens mosaicadas. Em nosso roteiro metodológico, essa é considerada a última etapa, apesar de ser opcional.

Entretanto, lembramos que a interpretação de imagens para os mapeamentos temáticos pode ocorrer de forma: visual, que depende da experiência do pesquisador; automática que é bastante questionada pela reduzida acurácia dos resultados e; semiautomática, que segundo Seabra e Cruz (2013), busca agregar vantagens dos dois processos anteriores, permitindo a edição manual dos dados gerados. Assim, no arquivo vetorial foram acrescentadas as classes Mineração e Fumaça, através da edição da tabela de atributo, associada, ao mapeamento final de cobertura e uso da terra.

Por fim, de modo a refletir a respeito dos resultados alcançados aplicou-se a análise de correlação. A análise de correlação é uma estatística básica para avaliação de variáveis que se inter-relacionam. Assim, aplicou-se o método estatístico de coeficiente de correlação linear de Pearson. O coeficiente de correlação de Pearson amostral, sem ponderação, é estimado pela (Equação 1):

$$
r=\frac{\sum_{i=0}^{n}\left(x_{i}-\bar{x}\right)\left(y_{i}-\bar{y}\right)}{\sqrt{\sum_{i=1}^{n}\left(x_{i}-\bar{x}\right)^{2}} \sqrt{\sum_{i=1}^{n}\left(y_{i}-\bar{y}\right)^{2}}}
$$

Onde: $x 1, x 2, . ., x n$ e $y 1, y 2, \ldots, y n x 1, x 2, \ldots, x n$ \{ldisplaystyle $\mathrm{x} \_\{1\}, x \_\{2\}$, Idots,$\left.x \_\{n\}\right\}$ y 1, y $2, \ldots, y n\left\{\right.$ Idisplaystyle $y \_\{1\}, y \_\{2\}, \mid$ dots,$\left.y \_\{n\}\right\}$ são os valores medidos de ambas as variáveis. $A$ análise correlacional indica a relação entre 2 variáveis lineares e, os valores sempre serão entre -1 e +1 . O sinal indica a direção, se a correlação é positiva ou negativa, e o tamanho da variável indica a força da correlação. Nessa análise foi aplicada a correlação entre as variáveis número de bovinos e a área desmatada, de modo a explicar os resultados das áreas desmatadas.

\section{Resultados e Discussão}

O resultado dos mapeamentos de cobertura e do uso da terra, de forma geral, propicia análises sob duas perspectivas, a espacial (qualitativa) e a quantitativa. $\mathrm{Da}$ primeira possibilidade, destaca-se a descrição do produto cartográfico elaborado, em que se apropria das relações espaciais entre a localização das classes de uso e cobertura da terra. Ou seja, o foco central é a configuração espacial. Já a análise 
quantitativa, normalmente divulgada em tabelas, apresenta as áreas das classes de uso e cobertura, em metragem e/ou porcentagens em relação a área total da unidade geográfica de análise que pode ser: a bacia hidrográfica, município, estado, região, etc. As duas formas de análises se complementam, pois, nem sempre pelo mapa é possível observar a análise quantitativa, e nem pelas tabelas é possível verificar a distribuição espacial.

Desse modo, a partir do mapa de cobertura (Figura 4) foi possível constatar que o município de Porto Velho, apesar de apresentar a maior área desmatada acumulada, como já referido, é um dos municípios do estado de Rondônia em que as florestas ainda ocupam grandes áreas de forma contínua.

Figura 4 - Levantamento da Cobertura e do Uso da Terra, município de Porto Velho, Rondônia.

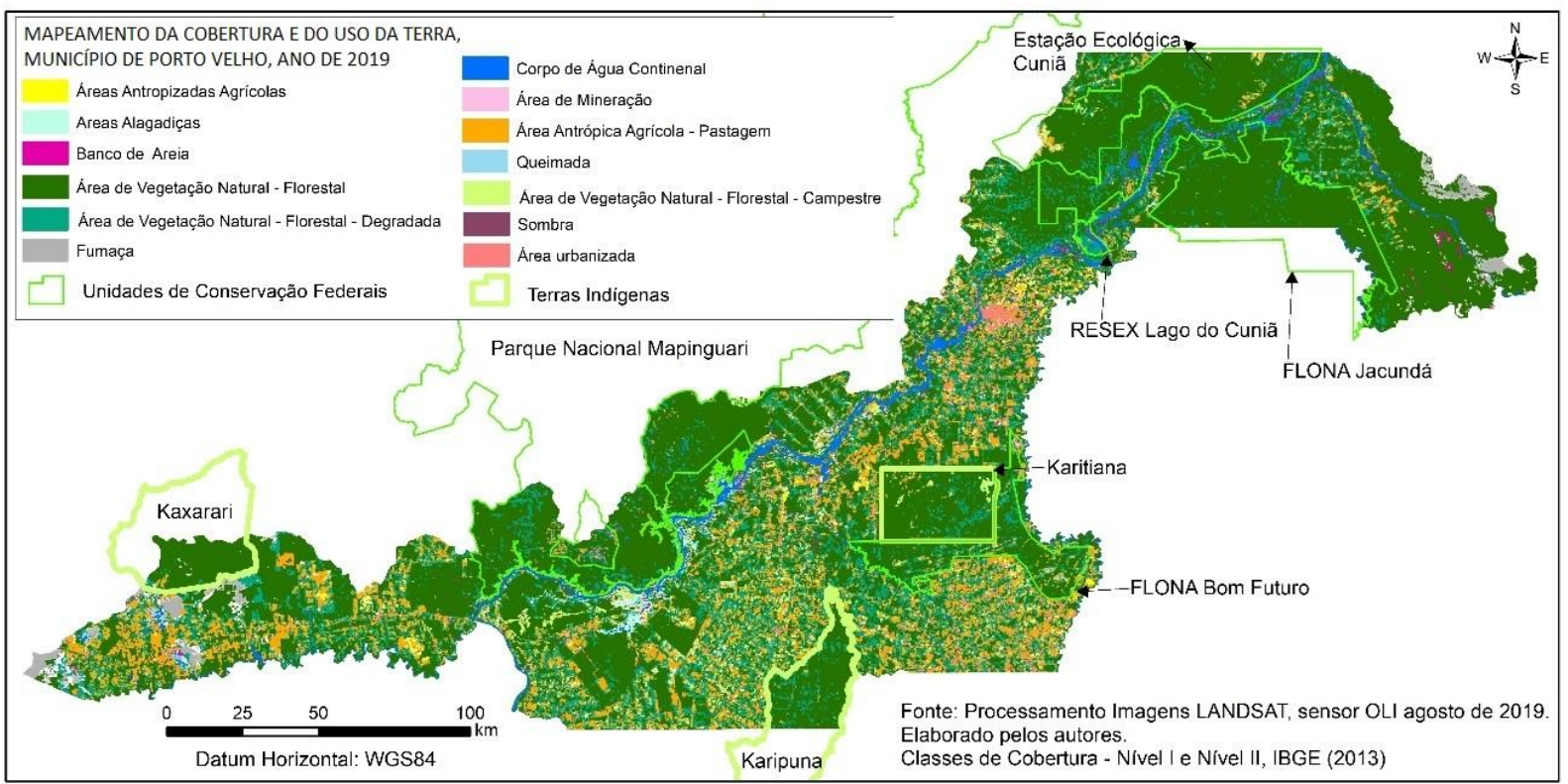

Fonte: elaborado pelos autores através do processamento das imagens LANDSAT, sensor OLI.

Apesar da adequabilidade do algoritmo Bhattacharya, a validação do processo de classificação revelou que a Exatidão Global, expressa pela razão entre os pontos corretamente classificados e o total de pontos de referência, foi de $80,29 \%$ das 86 amostras empregadas na validação. Valor este, abaixo do patamar estabelecido por Jensen (1986), mas aceito para a complexidade da área de estudo. Além disso, devido ao grande número de classes selecionadas, a matriz de erro não foi apresentada nesse artigo, mas será discutida a seguir.

Desse modo, os aspectos relevantes da precisão dos resultados desse tipo de análise, recaem sobre a confusão espectral dos alvos mapeados, indicada na matriz de erro. Assim, em síntese, a classe de uso Área Antrópica Agrícola - 
Pastagem apresentou maior confusão com a classe de uso Área Urbanizada e foram decisivas para o rebaixamento do valor da Exatidão Global.

Contudo, nossa experiência tem revelado que na maioria das cidades do estado de Rondônia são identificados lotes baldios, que se configuram como verdadeiros pastos dentro das cidades. Por consequência, a classe de cobertura de pastagens e a classe de uso urbano apresentam confusão considerável. Assim, algumas áreas de pastagens, eventualmente, podem ter sido mapeadas como parte das cidades ou núcleos urbanos.

A baixa expressividade das áreas de desmatamento no município de Porto Velho se deve a presença das Unidades de Conservação federal: Estação Ecológica do Cuniã; Parque Nacional do Mapinguari; Reserva Extrativista (RESEX) Lago do Cuniã; Floresta Nacional (FLONA) Jacundá e FLONA do Bom Futuro; parte das áreas das Terras Indígenas Kaxari e Karipuna e a área integral da Terra Indígena Karitiana. Resultado semelhante foi constatado também por Vasconcelos e Novo (2004), na região Amazônica que recobre os municípios do entorno do Reservatório de Tucuruí-PA. Utilizando imagens do sensor Thematic Mapper (TM), do LANDSAT 5 , os referidos autores observaram que a área mais protegida pertence a Terra Indígena Parakanãs, situada no município de Novo Repartimento.

Mesmo assim, em estudos realizados no entorno da Terra Indígena Karitiana, Santos (2018), observou pressão do desmatamento proveniente das fazendas que a circundam. Ademais, com base nos focos de queimadas disponibilizados pelo INPE, o referido autor (2018), concluiu que a Karipuna é a Terra Indígena de Rondônia mais afetada por essa prática. Ainda segundo Santos (2018), o fogo é usado por fazendeiros para "limpeza" de pastos e para estimular a rebrota das pastagens. $O$ fogo é utilizando ainda após o desmatamento para redução da biomassa e abertura de novas áreas, fomentando o domínio da atividade de pastagens.

Além disso, observou que a retirada da vegetação natural (Floresta) ocorre também para a prática da pecuária, no lado direito do Rio Madeira. Nessa porção do município, o desmatamento já está consolidado. Ao contrário, do lado esquerdo, observa-se o desmatamento do tipo padrão espinha de peixe, o que revela que a fronteira agrícola está em expansão, ou seja, em curso à direção do Parque Nacional do Mapinguari. O mapa revela ainda grandes áreas cobertas por fumaça, devido as práticas das queimadas, nas fronteiras sudoeste e nordeste do município.

As áreas de desmatamento mapeadas podem ser classificadas segundo a proposta de Saito et al. (2011), que revela os padrões de desmatamento do tipo 
consolidado, difuso, espinha de peixe, geométrico regular e unidirecional linear (Tabela 1).

Tabela 1 - Tipologia de padrão de desmatamento associados à ocupação humana para Amazônia Legal.

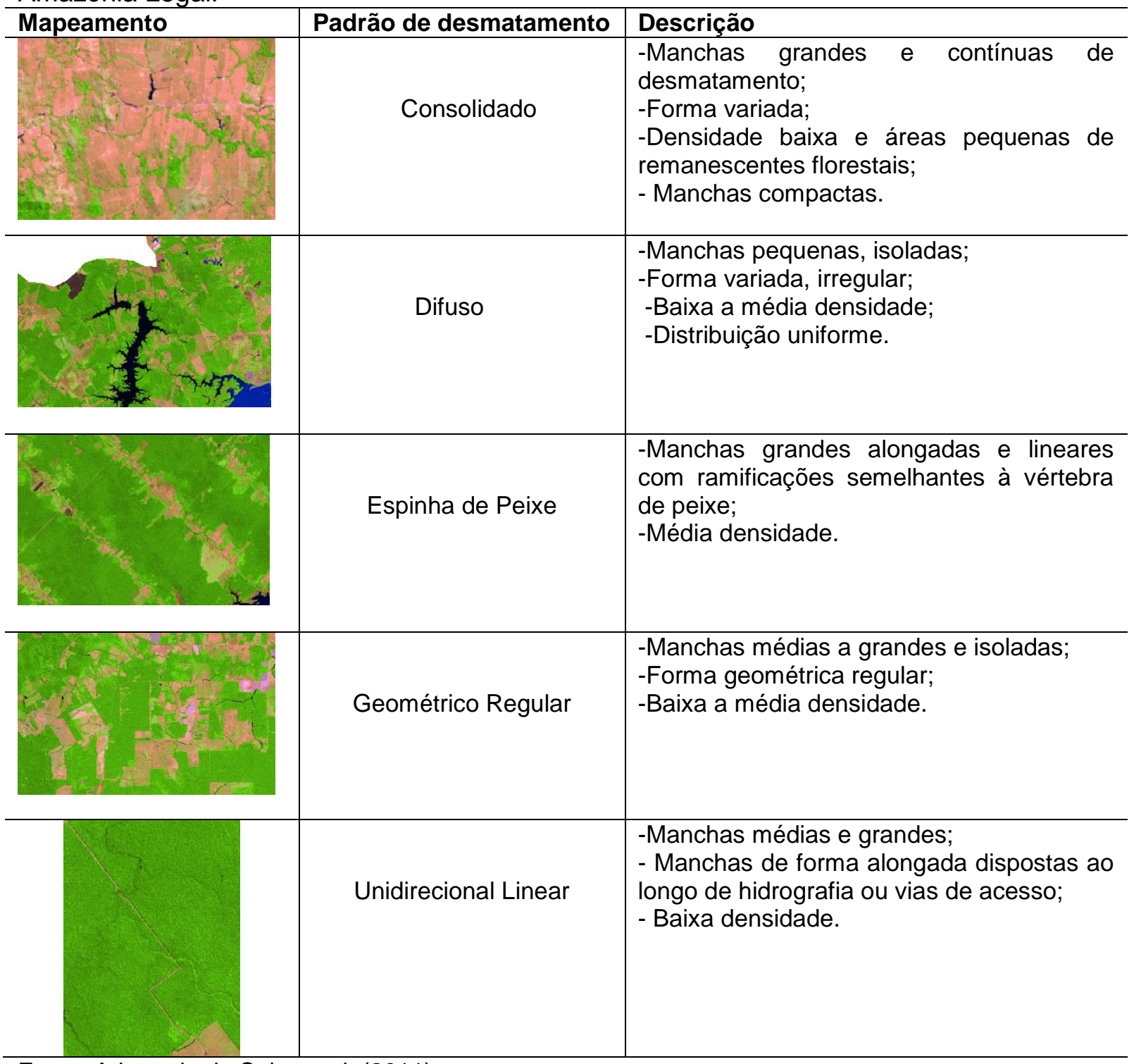

Fonte: Adaptado de Saito et al. (2011).

A análise quantitativa revelou que a classe de cobertura predominante é a Área de Vegetação Natural - Florestal, que cobre $64,03 \%$ do total da área do município de Porto Velho. A classe de uso antrópico predominante é a Área Antrópica Agrícola - Pastagem, que ocupou cerca de $17,26 \%$, do total da área do município (Tabela 2). 
Tabela 2 - Dados quantitativos de Cobertura e do Uso da Terra no município de Porto Velho - ano base (2019)

\begin{tabular}{l|r|r}
\hline Cobertura e Uso da Terra & Área em $\mathbf{~ m}^{2}$ & $\%$ \\
\hline Áreas Antropizadas Agrícolas & 171,05 & 0,50 \\
\hline Área Alagadiças & 294,74 & 0,86 \\
\hline Banco de Areia & 46,37 & 0,14 \\
\hline Área de Vegetação Natural - Florestal & $21.826,88$ & 64,03 \\
\hline Área de Vegetação Natural - Florestal - Degradada & $3.446,46$ & 10,11 \\
\hline Fumaça & 349,83 & 1,03 \\
\hline Corpo de Água Continental & 1044,31 & 3,06 \\
\hline Área de Mineração & 1,50 & 0,00 \\
\hline Área Antrópica Agrícola - Pastagem & $5.885,67$ & 17,26 \\
\hline Queimada & 246,11 & 0,72 \\
\hline Área de Vegetação Natural - Florestal - Campestre & 183,92 & 0,54 \\
\hline Sombra & 56,69 & 0,17 \\
\hline Área Urbanizada & 323,26 & 0,95 \\
\hline Total da área classificada & $33.876,79$ & 99,37 \\
\hline Área não classificada - abstenção & 214,16 & 0,63 \\
\hline
\end{tabular}

A pesquisa de Santos (2014) revela ainda que o município de Porto Velho possuía o maior rebanho bovino do estado, e um dos maiores do país. Para o autor, o grande número de bovinos pressiona a retirada da vegetação de floresta para formação de pastagens nesse município. Esse dado pode ser projetado para toda a Região Amazônica, pois segundo Rivero et al. (2009), "na Amazônia Brasileira a principal atividade responsável pelo desmatamento é a pecuária bovina”.

Assim, a partir dos resultados da análise, dos anos de 2000 a 2019, observou-se que a correlação entre o número de bovinos e a áreas de desmatamento foi elevada, $R^{2}=0,9649$. Desse modo, confirma-se que o aumento do número de bovinos contribuiu até o ano de 2019, para o aumento das áreas desmatadas no município de Porto Velho (Gráfico 1).

No gráfico representado a seguir é possível observar que os pontos estão próximos da linha de referência, o que corrobora com o resultado de alta correlação. Isto, permite evidenciar que o contínuo crescimento do rebanho bovino não está sendo acompanhado por projetos de criação de modo confinado, portanto, exigindo grandes áreas para pastos livres. 
Gráfico 1 - Correlação entre o número de rebanhos bovinos e a área desmatada no município de Porto Velho

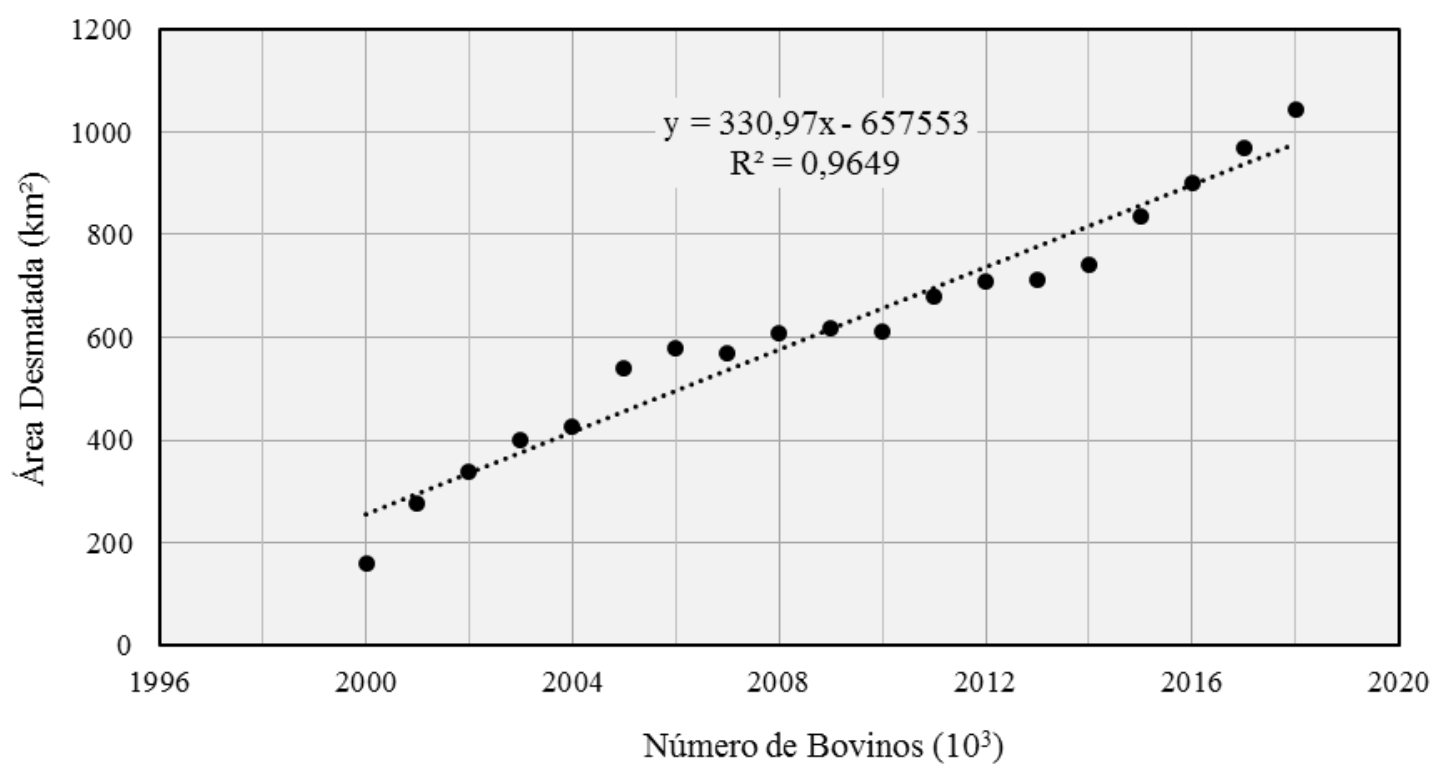

Fonte: Elaborado pelos autores.

Além da análise da correlação do período de 19 anos, o gráfico revela ainda, subperíodos em que o total anual de área desmatada e o número do rebanho bovino oscilaram. Desse modo, a redução da área desmatada em Rondônia seguiu uma tendência, que pode ser observada também, em outras parcelas da Região Amazônica. Isso pode ser explicado pelo Plano de Ação para Prevenção e Controle do Desmatamento na Amazônia Legal (PPCDAM), lançado em 2004. A partir dessas ações, observou-se que a taxa anual de desmatamento foi reduzida, atingindo 6.418 km² no período 2010-2011 (BRASIL, 2013b, p. 20).

Nesse sentido, é importante referir que o boi criado à solta (à pasto, sem confinamento) predomina no estado de Rondônia. Segundo Santos (2014), Rondônia busca se firmar como o The Natural Beef Cattle State ou o Estado Natural da Pecuária. O esforço ainda vai na valorização do lobby do "boi verde". Sua dinâmica revela, a criação de bovinos de corte, que de acordo com Pereira (2015) seria "no mais das vezes o gado nelore (zebuíno) criado de forma extensiva, em pastagens plantadas em áreas que normalmente aparecem como degradadas, pela prática agrícola ou mesmo resultantes de pastos pouco produtivos". Por fim, o esforço do governo é para que o boi seja simbolizado como produtividade "verde". Contudo a paisagem está se tornando cada vez mais, marrom, marcada pelas pastagens, que em certo período do ano, se encontram degradadas devido ao déficit hídrico. 


\section{Conclusões}

Os resultados permitiram concluir que:

- A classe de cobertura Área de Vegetação Natural - Florestal predomina no município de Porto Velho e cobre $64,03 \%$ do total de sua área. Esse resultado é fortemente alentado pela presença de Unidades de Conservação federais e terras indígenas, que apesar das pressões antrópicas, encontram-se com suas florestas preservadas, se comparadas com as áreas de entorno;

- A classe de uso antrópico predominante é a Área Antrópica Agrícola Pastagem, que ocupou cerca de $17,26 \%$, do total da área do município;

- O desmatamento ocorre sobremaneira para a formação de pastagens destinada a criação de gado bovino criado à solta, situação esta, comprovada pela correlação de Pearson.

A técnica de classificação automática pelo algoritmo Battacharya, associada a edição vetorial, mostrou ser bastante satisfatória para obter um melhor resultado de separabilidade das classes. Porém, em áreas de grande extensão territorial esta prática torna-se bastante trabalhosa, apresentando-se assim, como uma de suas principais limitações.

\section{REFERÊNCIAS}

ALMEIDA, C.A.; COUTINHO, A.C.; ESQUERDO, J.C.D.M.; ADAMI, M.; VENTURIERI, A.; DINIZ, C.G.; DESSAY, N.; DURIEX, L.; GOMES, A.R. High spatial resolution land use and land cover mapping of the Brazilian Legal Amazon in 2008 using Landsat-5/TM and MODIS data. Acta Amazônia, v. 46, n. 3, p. 291 - 302, 2016.

ARAÚJO FILHO, M.C.; MENESES, P.R.; SANO, E.F. Sistema de classificação de uso e cobertura da terra com base na análise de imagens de satélite. Revista Brasileira de Cartografia N. 59 (02), p. 171-179, 2007.

BESSA, J.C.M. Utilização de imagens de sensoriamento remoto de alta e média resoluções espaciais na geração de informação sobre ocupações urbanas como subsídio ao planejamento. $73 \mathrm{~F}$. Especialista em Sensoriamento Remoto e Sistemas de Informação Geográfica. São José dos Campos Dezembro, 2005.

BOGGIONE, G.A.; SILVA, M.V.A.; CARVALHO JUNIOR, N. R.; TELES, T.L.; NAZARENO, N.R.X. Definição da escala em imagens de sensoriamento remoto: uma abordagem alternativa. Anais... XIV Simpósio Brasileiro de Sensoriamento Remoto, Natal, Brasil, 25-30 abril 2009, INPE, p. 1739-1746.

BUTT, A.; SHABBIR, R.; AHMAD, S.S.; AZIZ, N.; NAWAZ, M. SHAN, M.T.A. Land cover classification and change detection analysis of Rawal watershed using remote sensing data. Journal of Biodiversity and Environmental Sciences, v. 6 (1), p. 236-248, 2015. 
BRAZIL, Ministério do Meio Ambiente. Plano de Ação para Prevenção e Controle do Desmatamento na Amazônia Legal (PPCDAm) 3를 Fase (2012-2015) pelo Uso Sustentável e Conservação da Floresta, 2013b. Disponível em: <http://combateaodesmatamento.mma.gov.br/images/conteudo/PPCDAM_3aFase.pdf>. Acesso em: 15 de jan. 2019.

CÂMARA, G.S. SOUZA, R.C.M, FREITAS, U.M., GARRIDO, J. "SPRING: Integrating remote sensing and GIS by object-oriented data modelling" Computers \& Graphics, 20: (3) 395403, May-Jun 1996.

CASIMIRO, P.C. Uso do Solo - Ecologia da Paisagem, Perspectivas de uma Nova Abordagem do Estudo da Paisagem em Geografia. Geolnova, oㅡ 2, p. 45-65, 2000.

CONGALTON, R.G. A review of assessing the accuracy classificatons of remotely sensed data. Remote Sensing Environment, v. 37, p.35-46, 1991.

FERANEC, J.; SOUKUP, T; HAZEU, G.; JAFFRAIN, G. European Landscape Dynamics: CORINE Land Cover Data. 1 ed. Lond New York: CRC Press - Taylor \& Francis Group, p. 367, 2016.

FERREIRA, E.; DANTAS, A.A.A.; MORAIS, A.R. Exatidão na classificação de fragmentos de matas em imagem do satélite Cbers-CCD, no município de Lavras, MG. Anais... XIII Simpósio Brasileiro de Sensoriamento Remoto, Florianópolis, Brasil, 21-26 abril 2007, INPE, p. 887-894.

Geotecnologias na Rede. Análise da exatidão/acuracidade de Classificação de Imagens via QGIS 3.4.15. Disponível em: https://www.youtube.com/watch?v=P--Y3fXmnpQ\&t=152s

Geotecnologias na Rede. Classificação supervisionada por pixel no SPRING. Disponível em: https://www.youtube.com/watch?v=d66hjTCwUUc

Geotecnologias na Rede. Classificação supervisionada de imagem por regiões no SPRING. Disponível em: <https://www.youtube.com/watch?v=A4P6WyOEbel\&t=12s>. Acesso em: 10 de abril de 2020.

HASSAN, Z.; SHABBIR, R.; AHMAD, S.S. MALIK, A.H.; AZIZ, N.; BUTT, A.; ERUM, S. Dynamics of land use and land cover change (LULCC) using geospatial techniques: a case study of Islamabad Pakistan. SpringerPlus, v. 5, p. 1-11, 2016.

IBGE - Instituto Brasileiro de Geografia e Estatística. Manual técnico de uso da terra. $3^{\text {a }}$ edição, Rio de Janeiro, 2013.

IBGE. Instituto Brasileiro de Geografia e Estatística. SIDRA-IBGE. Sistema IBGE de Recuperação Automática - SIDRA. Efetivo dos rebanhos, por tipo de rebanho. Disponível em: <https://sidra.ibge.gov.br/pesquisa/ppm/tabelas>. Acesso em 2 de abril de 2020.

INSTITUTO BRASILEIRO DE GEOGRAFIA E ESTATÍSTICA. Manual Técnico de Uso da Terra. 3를 Edição, Rio de Janeiro, 2013.

JENSEN, J. R. Introductory digital image processing. Englewood Cliffs: Prentice - Hall, 1986. $51 \mathrm{p}$.

KAUL, H.A.; SOPAN, I. Land Use Land Cover Classification and Change Detection Using High Resolution Temporal Satellite Data. Journal of Environment, v. 1, n. 4, pp. 146-15, 2012. 
MELO, F.P. Risco ambiental e ordenamento do território em Garanhuns - PE. 247 F. (Tese de Doutorado). Programa de Pós-Graduação em Geografia, Universidade Federal do Sergipe, 2016.

MELO, F.P.; SOUZA, R.M. Energia Eletromagnética na Superfície Terrestre: estimativa multitemporal do albedo em Garanhuns-PE. Ciência e Natura, v. 38, n.1, p. 170 - 178, 2016.

OLIVEIRA, P.C.S.S.; FERREIRA, N.C.; SANTOS, A.M. Análise da pressão antrópica, evapotranspiração e temperatura em áreas especiais no sul da Amazônia brasileira. Revista Geográfica Venezolana, v. 60, n. 1, p. 28-43, 2018.

PEREIRA, M.F.V. A modernização recente da pecuária bovina em Rondônia: normas territoriais e a nova produtividade espacial. Revista Geo UERJ, v. 26, p. 95-112, 2015.

RIVERO, S.; ALMEIDA, O.; ÁVILA, S.; OLIVEIRA, W. Pecuária e desmatamento: uma análise das principais causas diretas do desmatamento na Amazônia. Nova Economia, v. 19, n. 1, p. 41-66, 2009.

SAITO, E. A.; ESCADA, M. I. S.; FONSECA, L. M. G.; KORTING, T. S. Análise de padrões de desmatamento e trajetória de padrões de ocupação humana na Amazônia usando técnicas de mineração de dados. Anais... XV Simpósio Brasileiro de Sensoriamento Remoto - SBSR, Curitiba, PR, Brasil, 30 de abril a 05 de maio de 2011, INPE p. 2833-2840.

SANTOS, Relação entre uso do solo e comportamento hidrológico na Bacia Hidrográfica do Ribeirão João Leite. Revista Brasileira de Engenharia Agrícola e Ambiental, v. 14, n. 8, p. 826-834, 2010.

SANTOS, A. M. Cartografias dos povos e das Terras Indígenas em Rondônia. 314 F. (Tese de Doutorado). Setor Ciências da Terra, Departamento de Geografia, Programa Mestrado e Doutorado em Geografia, Universidade Federal do Paraná, Curitiba, 2014.

SANTOS, A.M.; GOMIDE, M.L. A ocupação no entorno das terras indígenas em Rondônia, Brasil. Boletim Goiano de Geografia, v. v. 35, n. 3, p. 417-436, 2015.

SANTOS, A.M.; MENDONÇA, A. Conflitos territoriais no Corredor Etnoambiental TupiMondé Rondônia-Mato Grosso. Terr@ Plural, v. 10 n. 2, p. 252-265, 2016.

SANTOS, A. M. Socioenvironmental impacts on indigenous lands in the south of the Brazilian Amazon. Amazonia Investiga, v. 7 (12), p. 123-135, 2018.

SEABRA, V. S. da; CRUZ, C. M. Mapeamento da Dinâmica da Cobertura e Uso da Terra na Bacia Hidrográfica do Rio São João, RJ. Revista Sociedade \& Natureza, v. 25 (2): 411426, 2013.

SOARES, D.O. Análise de mapeamento de uso e ocupação do solo, entre as metodologias do TerraClass cerrado 2013 e Corine Land Cover 2018, para o município de Cristalina Goiás, Brasil. 84 f. Mestrado em Ciência e Sistemas de Informação Geográfica. Nova Information Management School, 2020.

VASCONCELOS, C. H.; NOVO, E. M. L. M. de. Mapeamento do uso e cobertura da terra a partir da segmentação e classificação de imagens - fração solo, sombra e vegetação derivadas do modelo linear de mistura aplicado a dados do sensor TM/Landsat5, na região do reservatório de Tucuruí - PA. Acta Amazônica, v. 34, n.(3), p. 487 - 493, 2004. 
WISCHMEIER, W. H.; SMITH, D. D. Predicting rainfall erosion losses; a guide to conservation planning. Washington: U.S. Department of Agriculture, (Agriculture Handbook n. 537), 1978, 58p.

\section{NOTAS DE AUTOR}

\section{CONTRIBUIÇÃO DE AUTORIA}

Alex Mota dos Santos - Concepção. Coleta de dados, Análise de dados, Elaboração do manuscrito, revisão e aprovação da versão final do trabalho.

Fabrizia Gioppo Nunes - Concepção e elaboração do manuscrito. Participação ativa da discussão dos resultados; Revisão e aprovação da versão final do trabalho.

\section{FINANCIAMENTO}

Não se aplica.

\section{CONSENTIMENTO DE USO DE IMAGEM}

Não se aplica.

APROVAÇÃO DE COMITÊ DE ÉTICA EM PESQUISA

Não se aplica.

\section{CONFLITO DE INTERESSES}

Não se aplica.

\section{LICENÇA DE USO}

Este artigo está licenciado sob a Licença Creative Commons CC-BY-NC. Com essa licença você pode compartilhar, adaptar, criar para qualquer fim, sem uso comercial e desde que atribua a autoria da obra.

\section{HISTÓRICO}

Recebido em: 10-04-2020

Aprovado em: 13-07-2020 